\title{
O IMPACTO DA REMUNERAÇÃO DOS EXECUTIVOS NO FLUXO DE CAIXA OPERACIONAL DAS EMPRESAS LISTADAS NA B3
}

THE IMPACT OF EXECUTIVE COMPENSATION IN THE OPERATING CASH FLOWS OF THE COMPANIES LISTED ON THE B3

\section{Diego Saldo Alves}

Mestre em Ciências Contábeis pela Universidade do Vale do Rio dos Sinos (São Leopoldo/Brasil). Professor na Universidade Feevale (Novo Hamburgo/Brasil).

\section{Marcelo Paveck Ayub}

Mestre em Administração e Negócios pela Pontifícia Universidade Católica do Rio Grande do Sul (Porto Alegre/Brasil). Professor na Universidade Feevale (Novo Hamburgo/Brasil). 


\section{RESUMO}

O objetivo deste estudo é analisar qual o impacto da remuneração dos membros do conselho de administração e conselho fiscal no fluxo de caixa operacional das empresas brasileiras listadas na B3. Foram analisadas 84 empresas no período de 2012 a 2015. Na análise, foi feita uma regressão linear múltipla com dados em painel, além das estatísticas descritivas. Adotou-se o fluxo de caixa operacional como variável dependente e as remunerações dos membros do conselho de administração e conselho fiscal como variável independente. No estudo, utilizou-se o coeficiente de correlação de Pearson na intenção de medir o grau de correlação entre as variáveis. Como fundamentação teórica, foi analisada a demonstração dos fluxos de caixa, em que foram abordados o fluxo de caixa das atividades operacionais, investimento e financiamento. Também foram abordadas as formas de remuneração de executivos, como remuneração fixa e variável do conselho de administração, pagamento baseado em ações e opções de ações, remuneração fixa do conselho fiscal, a teoria da agência e estudos anteriores sobre o assunto. Os resultados evidenciam que não há relação significativa entre a remuneração dos executivos e o fluxo de caixa operacional das empresas, exceto a remuneração fixa do conselho fiscal que se apresentou positiva e significativa.

Palavras-chave: Remuneração dos executivos. Fluxo de caixa operacional. Pagamento baseado em ações.

\section{ABSTRACT}

The objective of this study is to analyze whether executive compensation influences the operational cash flow of Brazilian companies listed on B3. A total of 84 companies were analyzed between 2012 and 2015. In the analysis, a multiple linear regression with panel data was performed, in addition to the descriptive statistics. As a dependent variable, the net cash flow from operating activities was adopted and, as independent variables, the fixed compensation, variable and payment based on shares of the board of directors and the fixed compensation of the fiscal council. In the study, the Pearson correlation test was used to identify collinearity between the study variables. As a theoretical basis, the cash flow statement was analyzed, in which the cash flow from operating activities, investment and financing were discussed. Executive Compensation was also discussed, such as fixed and variable compensation of the board of directors, stock-based payment and stock options, fixed compensation of the supervisory board, agency theory and previous studies on the subject. The results show that there is no significant relationship between the executives 'compensation and the companies' operating cash flow, except for the fixed remuneration of the fiscal council, which was positive and significant

Keywords: Executive compensation. Operating cash flow. Share-based payment. 


\section{INTRODUÇÃO}

A remuneração dos executivos de uma empresa pode ser elaborada de diversas formas, desde que contemple a estratégia da organização, pois é uma forma de atrair os gestores desejados, mas principalmente avaliar o desempenho destes executivos a partir do momento em que os participantes do mercado analisam informações financeiras decorrentes de sua gestão (ANTHONY; GOVINDARAJAN, 2008).

A remuneração dos principais executivos pode ser de forma fixa e variável, de acordo com o porte da empresa e das políticas de remunerações. Muitas empresas oferecem pagamento baseado em ações ou opção de ações, em que o executivo recebe um percentual do capital da empresa como forma de motivar esses executivos a buscarem melhores resultados para as empresas.

Segundo Anjos et al. (2015), nos Estados Unidos é comum que a remuneração dos executivos tenha um valor variável elevado, em alguns casos o valor total pago aos executivos é todo variável, já no Brasil, os executivos preferem não arriscar ter uma remuneração variável elevada, devido ao fato de não atingirem os resultados esperados. A maior parcela da remuneração dos executivos brasileiros é fixa, mas as parcelas variáveis buscam incentivar o cumprimento de metas, sendo responsáveis pela atração, retenção e avaliação de profissionais nas empresas.

Na literatura, há diversos estudos comparando a remuneração de executivos com o desempenho das empresas, correlacionando indicadores financeiros como Retorno sobre Ativos (ROA), Lucro por Ação (LPA), também com indicadores de mercado como Índice de Valor de Mercado (IVM), Q de Tobin (QT) entre outros. Mas não foi encontrado nenhum estudo correlacionando a remuneração dos executivos com o fluxo de caixa operacional das empresas, e este é um assunto que já deveria ter sido abordado na literatura. Em um determinado período, uma empresa pode ter bons indicadores financeiros, mas com um fluxo de caixa operacional negativo, isso não é bom para as empresas, já que um número significativo de indicadores é apurado pelo regime de competência e não de caixa.

O Fluxo de Caixa Operacional de uma empresa pode ser analisado na Demonstração dos Fluxos de Caixa (DFC). No Brasil, as empresas brasileiras de capital aberto são obrigadas a divulgar a DFC, demonstração esta que é elaborada de acordo com o Pronunciamento Técnico CPC 03 - Demonstração dos Fluxos de Caixa, CPC, o qual está correlacionado com as Normas Internacionais de Contabilidade - IAS 7 - Statement of Cash Flows.

A DFC é um dos componentes mais importantes das Demonstrações Financeiras, pois permite aos investidores entender como as operações estão funcionando, qual a origem do dinheiro e como o dinheiro é aplicado. Uma empresa pode usar a DFC para prever futuros fluxos de caixa, ajudando os gestores na tomada de decisão em relação a orçamentos futuros (MEGAN et al., 2009). 
Diante deste contexto, remuneração de executivos e fluxo de caixa operacional, elaborouse o seguinte problema de pesquisa: Qual o impacto da remuneração dos membros do conselho de administração e conselho fiscal no fluxo de caixa operacional das empresas brasileiras listadas na B3?

Para responder o problema de pesquisa, tem-se como objetivo geral analisar qual o impacto da remuneração dos membros do conselho de administração e conselho fiscal no fluxo de caixa operacional das empresas brasileiras listadas na B3. Como objetivos específicos, analisar se remuneração fixa, remuneração variável e o pagamento baseado em ações para os membros do conselho de administração influenciam no fluxo de caixa operacional das empresas. Também analisar se a remuneração fixa dos membros do conselho fiscal influencia no fluxo de caixa operacional.

O estudo justifica-se pela importância do fluxo de caixa operacional nas empresas, e também como indicador de desempenho dos membros do conselho de administração e conselho fiscal que são remunerados. Esta pesquisa será útil para pesquisadores, gestores, acionistas que remuneram seus executivos de forma fixa e variável, já que este tema não foi abordado na literatura. Espera-se, por meio deste trabalho, reduzir a lacuna existente sobre o tema, analisando o impacto da remuneração dos executivos no fluxo de caixa operacional das empresas.

A amostra deste estudo é composta por 84 empresas listadas na B3 e para análise dos dados utilizou-se regressão linear múltipla com dados em painel. A variável dependente é o fluxo de caixa operacional e as variáveis independentes são: conselho de administração remuneração fixa e variável, conselho de administração pagamento baseado em ações e conselho fiscal remuneração fixa. 0 período analisado foi de 2012 a 2015, por esse motivo, adotou-se a regressão linear múltipla com dados em painel.

Este estudo está estruturado da seguinte forma: no tópico 1 compreende a Introdução com problema de pesquisa, objetivo geral, objetivos específicos e justificativa do estudo; no tópico 2, 0 Referencial Teórico aborda a Teoria da Agência, Remuneração de Executivos, Pagamento Baseado em Ações, Conselho de Administração, Conselho Fiscal e Demonstração dos Fluxos de Caixa; no tópico 3, os Aspectos Metodológicos; no tópico 4, a Análise dos Dados; e, no tópico 5, a Conclusão do Estudo. No tópico a seguir, o referencial teórico.

\section{REFERENCIAL TEÓRICO}

Neste tópico, é abordada a Demonstração dos Fluxos de Caixa, Remuneração dos Executivos, Teoria de Agência, Pagamento Baseado em Ações e estudos anteriores sobre o tema abordado. 


\subsection{TEORIA DA AGÊNCIA}

Jensen e Meckling definem o relacionamento de agência quando uma pessoa ou mais (principal) contratam outra pessoa (agente) para realização de atividades em seu nome ou a seu mando, delegando, ao agente, autoridade para assuntos específicos da organização.

Segundo Fontes Filho (2003), podem existir diferentes interesses entre o principal e o agente. Na separação entre gestão e propriedade, embora efetiva para garantir o investimento do proprietário em novos negócios, podem ocorrer problemas de relacionamento entre os gestores e os proprietários. 0 gestor ou agente pode não buscar os objetivos traçados pelo proprietário, ou não empregar o esforço necessário para a expansão do negócio, devido a interesses individuais do agente.

Marques e Conde (2000) afirmam que os conflitos entre o principal e o agente são inevitáveis, segundo os autores, devido à troca de uma remuneração, o agente deveria atuar conforme os interesses do principal, mas na prática, o agente tentará maximizar sua função de utilidade.

Para Jensen e Meckling (1976), os administradores das empresas possuem interesses que podem ser divergentes com os interesses dos acionistas, neste caso, ocorre o conflito de agência. Quando os administradores buscam a maximização do lucro em benefício próprio, em detrimento da utilidade dos acionistas, estes gestores podem expropriar a riqueza dos acionistas, já que poderão utilizar recursos da organização em benefício próprio.

Fama e Jensen (1983) argumentam que é possivel efetuar o controle dos problemas de agência. Para os autores, são necessários sistemas de decisão que dividam a gestão do controle em diversos níveis da organização. Os procedimentos utilizados para essa divisão podem incluir sistemas hierárquicos de decisão, em que niveis superiores funcionam para monitoramento e ratificação. Conselhos de Administração são responsáveis em ratificar e monitorar as decisões mais significativas para a empresa, também são responsáveis pela demissão, contratação, estipulação dos níveis de remuneração, compensação dos executivos e incentivos que encorajam o monitoramento mútuo entre os agentes.

A Teoria da Agência em muitos casos é considerada como uma teoria do comportamento humano, mas que deve ser observada como uma teoria sobre o desempenho e resultado dos agentes (performance outcome) (NILAKANT; RAO, 1994).

A forma como os executivos são remunerados pode influenciar no conflito de agência, principalmente quando os executivos recebem remuneração variável em função do desempenho, atingimento de metas, entre outros. No tópico seguinte é abordado sobre a remuneração dos executivos. 


\subsection{REMUNERAÇÃO DE EXECUTIVOS}

Há um longo debate sobre se a remuneração dos executivos pode ser melhor explicada pelo incentivo compativel da contratação ideal ou pelo comportamento gerencial de busca de renda. Sob a teoria da contratação ideal, os conselhos e os comitês de remuneração projetam acordos de remuneração de executivos para reduzir o problema de agência entre gestores e acionistas de forma a aumentar o valor para os acionistas (COLLINS; GONG; LI, 2009).

Na literatura, buscou-se estudos relacionados à remuneração dos executivos com o fluxo de caixa operacional, mas não foram encontrados, a maioria dos estudos relaciona a remuneração dos executivos com outros indicadores de desempenho como ROE, ROA, Q de Tobin entre outros. Beuren e Silva (2014) analisaram se a remuneração dos executivos está correlacionada com o desempenho e o tamanho das empresas brasileiras de capital aberto. Os autores analisaram uma amostra de 219 empresas, com dados do período de 2009 a 2011. Os resultados evidenciaram que a remuneração dos executivos é negativa, significativamente correlacionada com o tamanho da empresa. Em relação aos indicadores de desempenho está positivamente correlacionada. A conclusão do estudo é que há relação negativa entre o tamanho da empresa e a remuneração dos executivos e que há associação entre a remuneração dos executivos e o desempenho das empresas.

Alves e Krauter (2014) pesquisaram a relação entre a remuneração dos executivos e o desempenho financeiro das empresas que permaneceram no ranking, no período de 2007 a 2011, da pesquisa "As 150 Melhores Empresas para Você Trabalhar". Os autores encontraram, no estudo, uma relação negativa significativa entre o desempenho da organização e a remuneração variável. Não foi possível identificar fatores de remuneração associados a um desempenho financeiro superior.

A remuneração de executivos deve ser estratégica e deve considerar o contexto organizacional, o estilo gerencial, a estrutura, visão de futuro, entre outros. A remuneração estratégica deve ser concebida de maneira que canalize energias para o contexto dos interesses dos acionistas, auxiliando no alinhamento desses interesses a intenção de melhorar os resultados (BEUREN; SILVA, 2014).

Segundo Theiss e Beuren (2014) remunerar envolve aspectos cognitivos, e que se distingue de pessoa para pessoa, não representado somente por uma quantia em dinheiro, mas por regalias, benefícios, objetos e poder. É um tema que envolve todas as organizações, já que são formadas por pessoas remuneradas, as quais influenciam nos objetivos da empresa, principalmente o executivo da empresa que tem o poder de tomar decisões.

As ações gerencias não são totalmente observáveis pelos acionistas, também nem sempre é possivel saber se as ações estão direcionadas à maximização da riqueza dos acionistas. A segregação 
de propriedade e de controle aumenta a ocorrência de conflitos de interesse, ou seja, conflito de agência. Nesse caso, o acionista delega ao gestor o poder de decisão sobre sua propriedade. Muitas vezes o agente age em benefício próprio, em vez de tomar decisões que beneficie os interesses do principal (BEUREN; SILVA, 2014).

Um dos motivos para que haja conflito de agência é a forma de remuneração dos executivos. Dependendo de como o executivo é remunerado, este pode agir em benefício próprio ao invés de maximizar o lucro da empresa. Também há outros fatores que podem influenciar no conflito de agência que são difíceis de identificar, varia de gestor para gestor, mas a remuneração é um fator importante neste caso.

Wood Jr. e Picarelli Filho (2004) destacam os elementos centrais do sistema de remuneração nas empresas sendo: remuneração fixa (por competências, habilidades e benefícios que incluem a previdência complementar). Também há a remuneração por desempenho e a remuneração variável, que em alguns casos incluem a participação acionária. Os autores também mencionam que existem dois tipos de remuneração variável: a remuneração por resultados e a participação nos lucros.

Para Dias, Cunha e Mário (2009), o principal objetivo da remuneração variável é atrair mais atenção dos colaboradores, pois as empresas utilizam diversos métodos para fidelizar esses profissionais. Cada uma dessas ferramentas possui um tipo de abordagem diferente, na intenção de satisfazer e manter o quadro funcional, usufruindo toda capacidade intelectual por um período de tempo.

No Quadro 1, são evidenciados de forma resumida os tipos de remuneração.

\section{Quadro 1 - Tipos de Remuneração Fixa e Variável}

\begin{tabular}{|l|l|}
\hline \multicolumn{1}{|c|}{ Remuneração Fixa } & \multicolumn{1}{c|}{ Remuneração Variável } \\
\hline $\begin{array}{l}\text { Diretos: } \\
\text { - Salário Base } \\
\text { - } 13^{\circ} \text { Salário } \\
\text { - Férias }\end{array}$ & Gain Sharing: remuneração em função da redução de custos, produtividade. \\
$\begin{array}{l}\text { Indiretos: } \\
\text { - Assistência Médica } \\
\text { - Carro }\end{array}$ & Profit sharing: são os lucros distribuídos em um determinado perído. \\
- Auxilio Alimentação & Pay-for-performance: são gratificações, bônus pelo cumprimento de metas e resultados. \\
\hline
\end{tabular}

Fonte: Adaptado de Beuren e Silva (2014) 
Além da remuneração fixa e variável, tradicionalmente oferecida pelas empresas aos principais executivos, também há outra forma de incentivar estes executivos como por exemplo o pagamento baseado em ações que é abordado no tópico seguinte.

\subsection{PAGAMENTO BASEADO EM AÇÕES}

A prevalência generalizada do pagamento baseado em ações para altos executivos aumentou o interesse dos pesquisadores em avaliar se tais incentivos reduzem o desejo dos gestores em manipular os lucros, alinhando os interesses dos gestores e acionistas. No entanto, pesquisas extensas produziram uma relação mista e muitas vezes positiva entre a compensação de capital do CEO e a administração de resultados, ou seja, visão de agência (LI; KUO, 2017).

Segundo Martins et al. (2013), algumas empresas optam por remunerar seus empregados (administradores, executivos ou outros colaboradores) por meio de pacotes que incluem ações e opção de ações. Esta forma de remuneração é uma maneira de incentivar os funcionários a atingir determinadas metas, e também que eles se tornem donos da entidade ou que possam ganhar pela diferença entre o valor de mercado das ações subscritas e o valor da subscrição.

O pagamento baseado em ações visa incentivar os empregados da empresa a comprometerem-se com a maximização do valor da empresa, alinhando seus interesses e dos acionistas. Isso é necessário porque, de acordo com a Teoria de Agência, os empregados (agentes) em muitos casos possuem objetivos conflitantes com os acionistas (principais), ou seja, conflito de interesses (MARTINS et al., 2013).

Martins et al. (2013) definem uma transação de pagamento baseado em ações, como uma transação na qual a empresa recebe produtos ou serviços em troca de seus instrumentos patrimoniais, ou também adquire produtos ou serviços e assume uma obrigação com o fornecedor de efetuar o pagamento de um determinado valor baseado no preço de seus instrumentos patrimoniais. Um instrumento patrimonial pode ser definido como um título com participação nos ativos líquidos de uma empresa, ou seja, ativos menos passivos. Os autores mencionam que nos acordos com pagamento baseado em ações, os instrumentos patrimoniais mais utilizados pelas empresas são as ações e as opções de ações.

As ações representam a menor parcela que divide o capital de uma empresa, já as opções de ações são contratos que proporcionam aos seus detentores o direito de subscrever ações da empresa a um preço fixado ou determinável num período de tempo específico. Embora os detentores tenham o direito de subscrever as opções de ações, os mesmos não têm a obrigação de fazer tal subscrição.

A opção de ações a empregados é concedida pelas empresas a seus funcionários como forma de motivação a dar-Ihes o direito de compra de uma quantia específica de ações por um preço determinado 
em certo período de tempo. Em contraste, com as opções de ações negociadas publicamente, cujo prazo de vencimento geralmente é limitado a 1 ano, as opções de ações a empregados são instrumentos de médio e longo prazo, cuja duração é determinada pelo seu período de carência especificado e pagamento diferido (MAJEWSKA, 2015).

Segundo Marcon e Godo (2004), a remuneração por meio de opção de ações permite aos funcionários a compra de ações da empresa, atrelando os ganhos à valorização das ações no longo prazo. Nos Estados Unidos, esta forma de remuneração é conhecida como Stock Options e na Inglaterra como Share Options. No âmbito de finanças, opção é todo o contrato que permite ao seu titular o direito, mas não o dever, de comprar ou vender determinado bem pelo preço acordado no momento em que o contrato é efetivado.

Embora o valor de uma opção de compra de ações possa ser influenciado se a empresa subjacente for uma das partes contratantes, as características dos próprios contratos também são importantes. Contratos de opções negociadas são uniformes e simples. Seu valor depende da interação de seis variáveis, das quais cada uma é entrada para o modelo de Black-Scholes: (1) preço da ação definido pelo mercado; (2) preço de exercício definido pelo contrato; (3) estimativa da volatilidade futura das ações, vida útil restante da opção (estimada); (4) a taxa de retorno sem risco sobre a vida útil restante da opção (estimada); (5) prazo até o vencimento, fixado pelo contrato; e (6) Dividendo em dinheiro (estimado) (SELLERS; KING; HUANG, 2015).

Segundo Martins et al. (2013), umas das principais contribuições do modelo de Black e Scholes foi a redução do período de tempo, pois os autores evidenciam que a combinação específica da ação com um empréstimo pode duplicar uma opção de compra num horizonte de tempo infinitesimal.

Em relação aos estudos sobre pagamentos baseados em ações, não foi encontrado um estudo que relacione com o fluxo de caixa operacional, mas há estudos semelhantes que correlacionam com outros indicadores de desempenho, como o estudo de Marcon e Godo (2004), que analisaram a correlação entre os programas de remuneração por stock options e o desempenho financeiro das empresas. Os autores analisaram 32 empresas da Revista Exame - "100 melhores empresas para você trabalhar" - no período de 2000 a 2002. Em relação às empresas analisadas no estudo, as que remuneram por stock options apresentaram um desempenho superior ao seu setor.

Aboody, Johnson e Kasznik (2010) investigaram a relação entre a precificação de opção de ações de executivos e não executivos com o desempenho subsequente das empresas. A amostra foi composta por 1.364 empresas no período de 1990 a 1996. Os autores constataram que a precificação de opção de ações exibe um aumento mais acentuado nos fluxos de caixa operacionais nos cinco anos subsequentes do que um grupo de controle de empresas que não precificam, com um declínio semelhante no preço das ações. $\mathrm{O}$ aumento subsequente da performance é atribuído às empresas que incluem aos seus executivos a precificação. 
Sesil e Lin (2011) analisaram se o programa de remuneração de opção de ações para executivos afetou a produtividade das empresas nos cinco anos subsequentes. A amostra foi composta por 632 empresas americanas, e o período analisado foram os cinco anos subsequentes a 1997. No estudo, foi observado que a remuneração de executivos por meio de opção de ações aumenta a produtividade das empresas.

Neste tópico, foi abordado o Pagamento Baseado em Ações, o qual é objeto de estudo deste trabalho, que analisa o Pagamento Baseado em Ações para os membros do Conselho de Administração. No tópico a seguir, serão abordados o Conselho de Administração e o Conselho Fiscal.

\subsection{CONSELHO DE ADMINISTRAÇÃO E CONSELHO FISCAL}

O Conselho de Administração é responsável por toda governança da empresa e atua sob autoridade concedida pela lei. Compete ao Conselho de Administração fixar prioridades para as operações da empresa, convocar assembleias gerais de acionistas, fixar sua agenda, deliberar sobre emissões de obrigações, apresentar recomendações sobre o montante de dividendos, bem como outros assuntos (MURAVYEV, 2016).

Martínez (2015) destaca que o Conselho de Administração é um dos mecanismos-chave para o controle dos gestores, e que a separação entre propriedade e gestão, especialmente nas grandes empresas, muitas vezes torna esta uma situação de interesses divergentes e assimetria de informação entre os dois grupos. No entanto, a passividade por parte da propriedade faz com que os gestores acabem controlando a empresa, de modo que o Conselho de Administração deixa de cumprir o seu papel fundamental, que é o controle.

Segundo Silva, Santos e Almeida (2011), os Conselhos de Administração deixaram de ser "pró forma" e passaram por mudanças significativas ao longo do tempo, pois sempre thes conferiram amplos poderes para condução dos assuntos das empresas. Os regimes internos e a legislação estipularam critérios mais rigorosos para composição do conselho, e os membros do conselho passaram a ser cobrados e avaliados em relação aos seus interesses com os objetivos das empresas.

Fuente, Sánchez e Lozano (2017) destacam que os Conselhos de Administração das sociedades compõem-se essencialmente de dois grupos: os administradores internos, cujos vínculos contratuais Ihes permitem tomar decisões de gestão, bem como os administradores não executivos ou externos, que podem ser administradores independentes ou proprietários, estes últimos representando os acionistas majoritários. No que diz respeito à independência do Conselho de Administração, o número de gestores não executivos está positivamente correlacionado com um comportamento responsável e com a transparência. 
Ao compor o Conselho de Administração, a organização deve criar um ambiente que permita a livre expressão dos conselheiros. A empresa deve buscar diversidade de experiências, pessoas qualificadas, estilo de comportamento, para que se reúna as competências necessárias para o exercício de suas atribuições (IBGC, 2009).

No Quadro 2, é evidenciado um resumo das principais competências e qualificações do Conselho de Administração.

\section{Quadro 2 - Competências e Qualificações dos Membros do Conselho de Administração}

\begin{tabular}{|l|l|}
\hline Competências & Qualificações \\
\hline Experiência como executivo sênior & Motivação \\
\hline Experiência em gestão de pessoas & Visão estratégica \\
\hline Conhecimentos de finanças & Capacidade de trabalho em equipe \\
\hline Conhecimentos contábeis & Capacidade de entender relatórios contábeis \\
\hline Conhecimentos jurídicos & Capacidade de entender relatórios financeiros \\
\hline Contatos de interesse da organização & Noções de legislação societária \\
\hline
\end{tabular}

\section{Fonte: Adaptado IBGC (2010)}

Devido à decorrência de grande concentração de poder, os membros do Conselho de Administração, em sua maioria, são indicados pelo acionista controlador. Isso reduz a possibilidade de os conselhos terem uma postura ativa e independente, que é necessária para o cumprimento das atribuições legais de orientação dos negócios e a fiscalização da gestão dos executivos em favor de todos os acionistas. Na intenção de neutralizar esta postura, surge o Conselho Fiscal na estrutura de Governança Corporativa. 0 Conselho Fiscal fortaleceu-se nas empresas norte-americanas com a autorização da SEC, aceitando-o como agente controlador em substituição ao Comitê de Auditoria (TINOCO; ESCUDER; YOSHITAKE, 2011).

O Conselho Fiscal é parte integrante do sistema de governança nas empresas brasileiras. De acordo com o estatuto, pode ser permanente ou não. A instalação de um Conselho Fiscal dar-se-á por meio de um pedido de algum sócio ou por um grupo de sócios (IBGC, 2009).

No Quadro 3, são evidenciados os principais objetivos do Conselho Fiscal: 
Quadro 3 - Principais Objetivos do Conselho Fiscal

\begin{tabular}{l}
$\begin{array}{l}\text { Qualquer um dos seus membros pode fiscalizar os atos dos administradores e verificar o cumprimento } \\
\text { de seus deveres legais e estatutários. }\end{array}$ \\
\hline $\begin{array}{l}\text { Opinar sobre o relatório anual da administração, evidenciando em seu parecer as informações } \\
\text { necessárias à deliberação da Assembleia Geral. }\end{array}$ \\
\hline Analisar, a cada trimestre, as Demonstrações Financeiras elaboradas periodicamente pela companhia. \\
\hline Denunciar erros e fraudes detectados pelo Conselho Fiscal. \\
Examinar as demonstrações financeiras do exercício social e sobre elas opinar.
\end{tabular}

\section{Fonte: Adaptado IBGC (2010)}

Segundo pesquisas da KPMG (2008), a Securities Exchange Comission (SEC) concedeu, em 2003, uma permissão para que o Conselho Fiscal de empresas brasileiras com ações negociadas na bolsa dos Estados Unidos exercesse funções de Comitê de Auditoria. As empresas ainda continuam divididas, algumas possuem Comitê de Auditoria estruturado e outras possuem um Conselho Fiscal com função de Comitê de Auditoria.

Segundo Hemalin e Weisbach (2003), os conselhos são uma solução para alguns problemas organizacionais, determinados endogenamente nas empresas e que solucionariam problemas de agência comum em grandes corporações.

O conflito de agência entre o principal e o agente pode influenciar no desempenho da empresa, principalmente no fluxo de caixa, assunto que é tratado no tópico seguinte.

\subsection{DEMONSTRAÇÃO DOS FLUXOS DE CAIXA (DFC)}

Para os investidores, o fluxo de caixa reflete a saúde financeira da empresa. Basicamente, é melhor ter mais caixa disponível para as operações; no entanto, esta não é uma regra rígida, algumas vezes as empresas apresentam um resultado negativo no fluxo de caixa devido à estratégia de crescimento e expansão das operações. Ajustando ganhos, ativos e passivos, os investidores podem obter uma imagem do que algumas pessoas consideram o aspecto mais importante de uma empresa: quanto dinheiro é gerado pela empresa e quanto do dinheiro é gerado pelas operações da empresa (MEGAN et al., 2009). 
As informações dos fluxos de caixa são evidenciadas na Demonstração dos Fluxos de Caixa; no Brasil, há o Pronunciamento Técnico específico para esta demonstração. As empresas brasileiras que são obrigadas a divulgar a DFC devem seguir as orientações do Pronunciamento Técnico CPC 03 Demonstração dos Fluxos de Caixa.

A Demonstração dos Fluxos de Caixa (DFC) não era obrigatória no Brasil até a publicação da Lei 11.638/07, exceto em casos específicos, como, por exemplo, as empresas de energia elétrica e empresas participantes do Novo Mercado. Com a promulgação da Lei n 11.638/07, a elaboração da DFC se tornou obrigatória, e a DFC substituiu a Demonstração das Origens e Aplicações de Recursos (DOAR). Porém, a lei não tratou a forma como a DFC deveria ser apresentada e, para estabelecer regras de como as empresas devem elaborar e divulgar a Demonstração dos Fluxos de Caixa, o Comitê de Pronunciamentos Contábeis (CPC) emitiu o Pronunciamento Técnico CPC 03 - Demonstração dos Fluxos de Caixa, o qual foi aprovado pela CVM por meio da Deliberação nº 641/10 e também pelo Conselho Federal de Contabilidade (CFC) e Banco Central (MARTINS et al., 2013).

Segundo Almeida e Bezerra (2012), a Demonstração dos Fluxos de Caixa evidencia todos os recebimentos e pagamentos realizados em dinheiro em um determinado período. Desta forma, os fluxos de caixa apresentam as entradas e saídas de caixa e equivalentes de caixa. A DFC é apresentada classificando os fluxos de caixa em operacionais, investimentos e financiamentos, pois esta classificação gera informações por atividade, permitindo que os usuários das informações avaliem o impacto das atividades sobre a situação financeira da empresa.

Para Deo (2016), a Demonstração dos Fluxos de Caixa descreve o fluxo de caixa de uma perspectiva contábil: distingue as fontes e o uso do caixa, classifica o caixa em operacional, investimento e financiamento e, em seguida, desenvolve o impacto líquido sobre a posição do caixa das empresas. O fluxo de caixa operacional está relacionado com as principais operações do negócio e é o componente mais importante da demonstração. A DFC é um relatório anual e geralmente é apresentada pelo método indireto, método este que reconcilia o Lucro Líquido e os fluxos de caixa das atividades.

A elaboração da DFC pode ser feita pelo método direto ou pelo método indireto. Pelo método direto, a demonstração apresenta o valor exato que entrou e saiu de dinheiro no caixa da empresa na atividade operacional, por exemplo; enquanto pelo método indireto, parte do Lucro Líquido, acrescentando todas as despesas e excluindo todas as receitas que não afetam o caixa. O método indireto é uma maneira de demonstrar a diferença entre o lucro líquido e o fluxo de caixa e também a diferença entre do resultado econômico para o resultado financeiro (MACEDO et al., 2011).

A Demonstração dos Fluxos de Caixa possui alguns pontos polêmicos em relação a classificação de juros e dividendos pela International Accounting Standards Board (IASB), órgão responsável pela 
emissão das Normas Internacionais de Contabilidade. O CPC 03 - Demonstração dos Fluxos de Caixa está relacionado com a norma internacional IAS 7 - Statement of Cash Flows.

Silvestre e Malaquias (2015) mencionam que não existe consenso quanto à classificação dos juros e dividendos, se devem ser classificados como operacionais, investimento ou financiamento. O CPC sugere às empresas que juros recebidos ou pagos, dos juros sobre capital próprio e dividendos recebidos, sejam classificados como atividade operacional; já os juros sobre capital próprio e dividendos pagos, sejam classificados como atividade de financiamento, e que uma alternativa diferente da recomendada pelo CPC deve ser evidenciada em nota explicativa.

Para melhor exemplificar as atividades operacionais, investimentos e financiamento, é evidenciado, no Quadro 4, um resumo das principais atividades.

Quadro 4 - Resumo de Atividades na Demonstração dos Fluxos de Caixa

\begin{tabular}{|c|c|c|}
\hline Operacional & Investimento & Financiamento \\
\hline - Recebimento de Vendas & - Recebimento Venda de Imobilizado & $\begin{array}{l}\text { - Empréstimo obtido em } \\
\text { Instituições Financeiras }\end{array}$ \\
\hline $\begin{array}{l}\text { - Recebimento de Juros sobre } \\
\text { Empréstimos Concedidos }\end{array}$ & $\begin{array}{l}\text { - Recebimento da venda de } \\
\text { participações em outras empresas }\end{array}$ & - Venda de Ações Emitidas \\
\hline $\begin{array}{l}\text { - Pagamento de Fornecedores } \\
\text { de Matéria-Prima }\end{array}$ & $\begin{array}{l}\text { - Pagamento por Aquisição de } \\
\text { Imobilizado }\end{array}$ & $\begin{array}{l}\text { - Pagamento de } \\
\text { Empréstimos Obtidos }\end{array}$ \\
\hline - Pagamento de Impostos & $\begin{array}{l}\text { - Pagamento pela aquisição em } \\
\text { outras sociedades }\end{array}$ & $\begin{array}{l}\text { - Pagamento do principal de } \\
\text { imobilizado adquirido a prazo }\end{array}$ \\
\hline
\end{tabular}

Fonte: Elaborado pelo autor (2017)

Neste tópico, foi abordado o referencial teórico relacionado com o tema da pesquisa, no tópico seguinte, serão abordados os aspectos metodológicos.

\section{ASPECTOS METODOLÓGICOS}

A amostra deste estudo é composta por 84 empresas listadas na B3 que remuneraram os executivos do conselho de administração e conselho fiscal no período de 2012 a 2015. Para seleção da amostra, foram consideradas as empresas que, em todos os anos do estudo, remuneraram pelo menos o 
conselho de administração e o conselho fiscal, pois as empresas que remuneraram somente o conselho de administração ou somente o conselho fiscal foram excluídas da amostra. Os dados foram coletados na página eletrônica das empresas pertencentes à amostra, destas foram coletadas as Demonstrações dos Fluxos de Caixa e os Formulários de Referências.

Para responder o problema de pesquisa, "Qual o impacto da remuneração dos membros do conselho de administração e conselho fiscal no fluxo de caixa operacional das empresas brasileiras listadas na B3?" adotou-se como variável dependente o fluxo de caixa líquido das atividades operacionais, valores estes que foram coletados da Demonstração dos Fluxos de Caixa das empresas, e como variáveis independentes utilizou-se a remuneração fixa do conselho de administração, remuneração variável do conselho de administração, pagamento baseado em ações do conselho de administração e remuneração fixa do conselho fiscal.

Nenhuma empresa contemplada na amostra apresentou remuneração variável para o conselho fiscal, por este motivo, não é objeto de estudo. As variáveis independentes foram coletadas do formulário de referência das empresas. No Quadro 5, são apresentadas as características das variáveis:

\section{Quadro 5 - Resumo das Variáveis}

\begin{tabular}{|l|l|l|l|}
\hline Código Variáveis & Variáveis & Classificação & Coleta \\
\hline FCO & $\begin{array}{l}\text { Fluxo de Caixa Líquido das } \\
\text { Atividades Operacionais }\end{array}$ & Variável Dependente & $\begin{array}{l}\text { Demonstração dos } \\
\text { Fluxos de Caixa }\end{array}$ \\
\hline CARF & $\begin{array}{l}\text { Conselho de Administração } \\
\text { Remuneração Fixa }\end{array}$ & Variável Independente & Formulário de Referência \\
\hline CARV & $\begin{array}{l}\text { Conselho de Administração } \\
\text { Remuneração Variável }\end{array}$ & Variável Independente & Formulário de Referência \\
\hline CAPBA & $\begin{array}{l}\text { Conselho de Administração } \\
\text { Pagamento Baseado em Ações }\end{array}$ & Variável Independente & Formulário de Referência \\
\hline CFRF & Conselho Fiscal Remuneração Fixa & Variável Independente & Formulário de Referência \\
\hline
\end{tabular}

\section{Fonte: Elaborado pelo autor (2017)}

Devido às características dos dados deste estudo, optou-se em trabalhar com regressão linear múltipla, pelo método dos mínimos quadrados ordinários com dados em painel. Para Costa Neto (2002), 
utiliza-se regressão linear múltipla quando o objetivo é estudar uma variável "y", em função de duas ou mais variáveis independentes. 0 método dos mínimos quadrados ordinários é uma técnica de otimização matemática que busca encontrar o melhor ajuste para um conjunto de dados.

Para dados em painel há diferentes modelos, pois a diferença básica entre os modelos está atrelada à existência de efeitos fixos e efeitos aleatórios. Neste estudo, foi aplicado o Teste de Hausman e o resultado para o melhor modelo foi o Efeito Aleatório. Para análise dos dados, foi utilizado o Software Eviews 9.5 que calculou o seguinte modelo:

$$
\mathrm{FCO}=\beta 0+B 1(\mathrm{CARF})_{\text {it }}+\beta 2(\mathrm{CARV})_{i \mathrm{t}}+\beta 3(\mathrm{CAPBA})_{i \mathrm{t}}+\beta 4(\mathrm{CFRF})_{\text {it }}+\mathrm{erro}_{\mathrm{it}}
$$

No estudo, foi feita uma análise descritiva das variáveis, também se aplicou o teste de Matriz de Correlação de Pearson, que tem como objetivo medir o grau de correlação entre duas variáveis. Callegarijacques (2003) sugere que o teste de Matriz de Correlação seja interpretado conforme evidenciado no Quadro 6.

\section{Quadro 6 - Interpretação de Correlação}

\begin{tabular}{|l|l|}
\hline Parâmetros & Interpretação \\
\hline se $0,00<\hat{\rho}<0,30$ & Existe fraca correlação linear \\
\hline se $0,30 \leq \hat{\imath}<0,60$ & Existe moderada correlação linear \\
\hline se $0,60 \leq \hat{\rho}<0,90$ & Existe forte correlação linear \\
\hline se $0,90 \leq \hat{\imath}<1,00$ & Existe correlação linear muito forte \\
\hline
\end{tabular}

Fonte: Elaborado pelo autor (2017)

O coeficiente de correlação de Pearsonjustifica-se devido àutilização de duas variáveis independentes com o mesmo comportamento (colinearidade), pois prejudicaria os estimadores (beta) do modelo. $\mathrm{Na}$ Tabela 1, é evidenciado o Teste de Correlação de Pearson na intenção de evitar a multicolinearidade entre as variáveis independentes. 
Tabela 1 - Teste de Correlação de Pearson

\begin{tabular}{c|c|c|c|c|c}
\hline & FCO & CARF & CARV & CAPBA & CFRF \\
\hline FCO & 1,00 & & & & \\
CARF & 0,17 & 1,00 & & & \\
CARV & 0,07 & 0,47 & 1,00 & & \\
CAPBA & 0,03 & 0,05 & 0,20 & 1,00 & \\
CFRF & 0,24 & 0,40 & 0,22 & $-0,04$ & 1,00 \\
\hline
\end{tabular}

Fonte: Elaborado pelo autor (2017)

A matriz de correlação evidenciada na Tabela 1 demonstra correlação fraca e correlação moderada entre as variáveis, conforme intepretação de Callegari-Jacques (2003). Não há problemas de multicolinearidade, já que a correlação entre todas as variáveis é inferior a 0,60.

Após verificar que não há problema de multicolinearidade entre as variáveis do estudo, aplicou-se uma regressão linear múltipla com dados em painel, em que são analisadas 84 empresas brasileiras de capital aberto no período de 2012 a 2015. Neste tópico, foram abordados os aspectos metodológicos e, no tópico seguinte, será abordada a análise dos dados.

\section{ANÁLISE DOS DADOS}

Inicialmente, realizou-se uma análise descritiva da variável dependentee das variáveis independentes do estudo. As medidas utilizadas foram média, mediana, máximo, mínimo, o teste Jarque-Bera (JB), juntamente com o Prob, na intenção de verificar se os dados são distribuídos normalmente. Na Tabela 2, é evidenciado um resumo estatístico das variáveis. 
Tabela 2 - Análise descritiva das variáveis do estudo

\begin{tabular}{lllll|l}
\hline & FCO & CARF & CARV & CAPBA & CFRF \\
Média & $172.004,4$ & $924.531,0$ & $210.613,1$ & $42.840,8$ & $167.219,1$ \\
Mediana & $76.345,5$ & $530.000,0$ & 0,0 & 0,0 & $147.000,0$ \\
Máximo & $986.000,0$ & $6.993 .527,0$ & $4.637 .426,0$ & $2.785 .302,0$ & $1.512 .000,0$ \\
Mínimo & $-676.047,0$ & 0,0 & 0,0 & 0,0 & 0,0 \\
\hline & & & & $79.115,3$ & $1.378,3$ \\
\hline Jarque-Bera & 79,9 & $1.041,9$ & $4.690,8$ & 0,0 & 0,0 \\
\hline
\end{tabular}

Fonte: Elaborado pelo autor (2017)

As estatísticas JB evidenciaram que as variáveis não possuem distribuição normal em nenhum dos casos. Embora não viole nenhuma das premissas básica do modelo de regressão linear, não é possivel realizar testes de hipóteses ou previsão. Para estes testes, exige-se Xi N( $\left.\mu, 0^{2}\right)$ (GUJARATI, 2006).

Observa-se na, Tabela 2, que o valor mínimo da remuneração dos executivos é zero, ou seja, em algumas empresas pelos menos 1 tipo de remuneração do estudo não foi paga aos executivos da empresa. Já a remuneração máxima ultrapassa 1 milhão de reais em algumas empresas.

O modelo de regressão procurou identificar a relação entre a remuneração dos executivos, especificamente do conselho de administração e conselho fiscal com o Fluxo de Caixa Operacional das empresas, conforme evidenciado na Tabela 3. 
Tabela 3 - Análise do modelo proposto

\begin{tabular}{|c|c|c|c|c|}
\hline \multicolumn{5}{|c|}{ FCO $=\beta 0+\beta 1(C A R F) i t+\beta 2(C A R V) i t+\beta 3($ CAPBA)it $+\beta 4($ CFRF)it + erroit } \\
\hline $\begin{array}{c}\text { Variáveis } \\
\text { Independentes }\end{array}$ & Coeficiente & Erro Padrão & t-Estatístico & Prob \\
\hline CONSTANTE & $103.776,4000$ & $30.902,8600$ & 3,3500 & 0,0009 \\
\hline CARF & 0,0028 & 0,0161 & 0,1791 & 0,8580 \\
\hline CARV & 0,0114 & 0,0249 & 0,4582 & 0,6471 \\
\hline CAPBA & 0,0183 & 0,0592 & 0,3098 & 0,7569 \\
\hline CFRF & 0,3722 & 0,0935 & 3,9771 & 0,0001 \\
\hline $\begin{array}{c}\text { Variável } \\
\text { Dependente }\end{array}$ & FCO & & & \\
\hline $\mathrm{R}^{2}$ & 0,0531 & & & \\
\hline Adj. $R^{2}$ & 0,0414 & & & \\
\hline F-statistic & 4,5202 & & & \\
\hline Prob (F-statistic) & 0,0014 & & & \\
\hline Hausman Test & 0,7328 & & & \\
\hline
\end{tabular}

Fonte: Elaborado pelo autor (2017)

Conforme resultados obtidos na Tabela 3, é possivel identificar que todas as variáveis independentes possuem correlação positiva em relação a variável dependente, ou seja, para cada aumento na remuneração dos executivos, há um aumento no valor do Fluxo de Caixa Operacional das empresas. Embora haja uma relação positiva, as variáveis CARF, CARV e CAPBA não são significativas ( $p$-value $>0,10$ ), já a variável CFRF apresenta-se significativa a um nivel de significância de $1 \%$ ( $p$-value $<0,01$ ) e um coeficiente de 0,3722. Em relação ao $R^{2}$ Ajustado, o modelo proposto explica apenas $4 \%$ da variável FCO.

Em relação ao Pagamento Baseado em Ações conforme evidenciado na Tabela 3, a variável CAPBA apresentou uma relação positiva, mas não significativa, diferente do estudo de Marcon e Godo (2004), que 
detectaram que as empresas que remuneram por Stock Options possuem desempenho superior ao seu setor.

No estudo, não é possível identificar de forma clara um conflito de agência, mas os resultados evidenciam que não há correlação entre a remuneração dos executivos do conselho de administração e o fluxo de caixa operacional das empresas, pois há indícios que os sistemas de remuneração do conselho de administração utilizados neste estudo não são suficientes para alinhar os interesses do agente com os do principal, já que o interesse do acionista é a maximização do lucro, desta forma, é necessário ter um fluxo de caixa operacional compatível com a remuneração dos executivos.

A relação positiva da remuneração do conselho fiscal com o fluxo de caixa operacional pode ser um indício de que os conselhos são uma solução para alguns problemas organizacionais, e que solucionariam problemas de agência comuns em grandes empresas, conforme menciona Hemalin e Weisbach (2003). 0 conselho fiscal deve ser visto como um controle independente para os sócios, na intenção de agregar valor para a empresa, pois uma das funções do conselho fiscal é denunciar, por qualquer de seus membros, erros, fraudes, além de sugerir providências à companhia (IBGC, 2009). Essa função de controle e fiscalização inibe os gestores de cometerem erros, fraudes, proporcionando uma melhor gestão e melhores resultados no caixa da empresa.

Pode-se inferir que, em um conselho fiscal bem remunerado, seus membros estarão mais motivados em fiscalizar os gestores e operações da empresa, gerando, por parte dos gestores da empresa, um cuidado maior em operar de forma correta, evitando conflito de agência. Um conselho motivado e bem remunerado terá uma dedicação maior em buscar embasamento para opinar sobre questões estratégicas da empresa, de forma a cooperar com melhores decisões, melhorando o desempenho da empresa, assim como o fluxo de caixa operacional.

Conclui-se aqui a análise dos dados do estudo, a seguir as considerações finais e recomendações para estudos futuros.

\section{CONSIDERAÇÕES FINAIS}

O objetivo deste estudo foi verificar se a remuneração dos executivos influencia no fluxo de caixa operacional das empresas brasileiras listadas na B3. Especificamente, foi analisado se as remunerações fixa, variável e o pagamento baseado em ações do conselho de administração influenciam no fluxo de caixa operacional das empresas. Além do conselho de administração, também foi analisada a remuneração fixa do conselho fiscal. 
Considerando o modelo utilizado no estudo, de modo geral, os resultados não evidenciaram influência significativa na remuneração dos executivos em relação ao fluxo de caixa operacional. Apenas a remuneração fixa do conselho fiscal apresentou nivel de significância de 1\%, enquanto as demais variáveis do estudo não foram significativas. As variáveis analisadas possuem pouco poder de explicação em relação ao fluxo de caixa operacional, pois o $\mathrm{R}^{2}$ ajustado foi de $4 \%$.

O estudo pautou-se na teoria da agência, que defende a utilização de sistemas de remuneração dos executivos com o intuito de alinhar os interesses do agente com os do principal, por esta razão, testou-se a relação entre a remuneração dos executivos e o fluxo de caixa operacional das empresas. Conclui-se, neste estudo, que a remuneração dos executivos do conselho de administração não influencia no fluxo de caixa operacional das empresas analisadas, já a remuneração do conselho fiscal exerce influência no fluxo de caixa operacional das empresas.

Adicionalmente, é importante destacar que os resultados obtidos nesta pesquisa não devem ser generalizados, devido ao tamanho da amostra, mas podem ser considerados consistentes na sua qualidade e extensão.

Como contribuição teórica, o estudo pode avançar em relação à teoria da agência e remuneração dos executivos, assim como aprofundar as análises sobre as formas de remuneração, as funções do conselho de administração e conselho fiscal. Em relação às limitações metodológicas, o tamanho da amostra pode contribuir para a não significância estatística das variáveis analisadas.

Por fim, como proposta para estudos futuros, sugere-se um estudo com um número maior de empresas, tanto com empresas brasileiras quanto empresas estrangeiras. Também sugere-se investigar se o perfil do conselho de administração influencia no fluxo de caixa operacional da empresa.

\section{REFERÊNCIAS}

ABOODY, David; JOHNSON, Nicole Bastian; KASZNIK, Ron. Employee Stock Options and Future Firm Performance: Evidence from Option Repreicings. Journal of Accounting and Economics, v. 50, p. 74-92, 2010.

ALVES, Marlon Fernandes Rodrigues; KRAUTER, Elizabeth. Remuneração executiva: Existe contribuição para a performance da organização? GCG Georgetown University - Universia. v. 8, n. 2, p. 55-69, 2014.

ANJOS, Luiz Carlos Marques dos; MONTE, Paulo Aguiar do; TAVARES, Márcia Ferreira Neves; LUSTOSA, Paulo Roberto Barbosa. Relação entre controle acionário e remuneração de executivos. Enfoque: Reflexão Contábil, v. 34, n. 1 p. 45-56, 2015. 
ANTHONY, R. N; GOVINDARAJAN, V. Sistemas de Controle Gerencial. 12 ed. São Paulo: McGraw-Hill, 2008.

BEUREN, Ilse Maria; SILVA, Marcia Zanievicz da. Remuneração dos executivos versus desempenho das empresas. FACES Journal Belo Horizonte, Belo Horizonte, v. 13, n. 2, p. 8-25, 2014.

BRASIL, Lei n 11.638, de 28 de dezembro de 2007. Altera e revoga dispositivos da Lei nº 6.404 , de 15 de dezembro de 1976, e da Lei $n^{\circ}$ 6.385, de 7 de dezembro de 1976, e estende às sociedades de grande porte disposições relativas à elaboração e divulgação de demonstrações financeiras. Disponivel em: <http://www. planalto.gov.br/ccivil_03/_ato2007-2010/2007/lei//11638.htm>Acesso em: 17 fev. 2017.

COLLINS, Daniel W; GONG, Guojin; LI, Haidan. Corporate Governance and Backdating of Executive Stock Options. Contemporary Accounting Research, v. 26, n. 2, 2009

COSTA NETO, Pedro Luiz de Oliveira. Estatística. 2 ed. São Paulo, 2002.

DEO, Prakash. Evaluating a Cash Flow Statement. International Journal of Business, Accounting and Finance. Houston, v. 10, n. 1, 2016.

DIAS, Warley de Oliveira; CUNHA, Jacqueline Veneroso Alves da; POUERI DO CARMO. Plano de Incentivo em Opções de Ações e a Harmonização Contábil: Estudo do Nívl de Disclosure das Empresas Brasileiras após o CPC 10. Pensar Contábil. Rio de Janeiro, v. 11, n. 46, p. 20-38, 2009.

FAMA, Eugene Francis; JENSEN, Michael C. Agency Problems and Residual Claims. Journal of Law \& Economics, v. 26, 1983.

FONTES FILHO, Joaquim Rubens. Governança Organizacional Aplicada ao Setor Público. In: CONGRESSO INTERNACIONAL DEL CLAD SOBRE LA REFORMA DEL ESTADO Y DE LA ADMINISTRACIÓN PÚBLICA. Anais... Panamá, 2003.

FUENTE, J.A; SÁNCHEZ, I.M. García; LOZANO, M.B. The Role of the Board of Directors in the Adoption of GRI Guidelines for the Disclosure of CSR Information. Journal of Cleaner Production, 2017.

GUJARATI, Damodar N. Econometria Básica. 4. ed. Rio de Janeiro: Campus, 2006.

HERMALIN, Benjamin E; WEISBACH, Michael S. Boards of directors as an endogenously determined institution: a survey of the economic literature. Economic Policy Review, p. 7-26, 2003.

IBGC - INSTITUTO BRASILEIRO DE GOVERNANÇA CORPORATIVA. 2009. Código das melhores práticas de governança corporativa. 4. ed. São Paulo, IBGC, 73 p. 
JENSEN, Michael C; MECKLING, William H. Theory of the firm: managerial begavior, agency costs and ownership structure. Journal of Financial Economics, v. 3, n. 4, p. 305-360, 1976.

KPMG. A Governança Corporativa e o Mercado de Capitais: Um panorama atual das corporações brasileiras na Bovespa e nas Bolsas norte-americanas. Pesquisa da KPMG Auditores Independentes em 2008. Disponivel em: <http://www.ceg.org.br/arquivos/A_Governanca_Corporativa.pdf >. Acesso em: $01 \mathrm{fev}$. 2017.

MARCON, Rosilene; GODO, Christine Kleinubing. Desempenho Financeiro das Empresas e Remuneração por Stock Options: Um Estudo Multissetorial. Revista de Administração FACES Journal, Belo Horizonte, v. 3, n. 1, p. 59-76, 2004.

MARQUES, Maria Conceição da Costa; CONDE, Maria Fátima Travassos. Teoria da Sinalização e da Agência. OROG Revisores \& Empresas, p. 39-45, 2000.

MARTínEZ, María Consuelo Pucheta. El papel del Consejo de Administración em la creación de valor en la empresa. Revista de Contabilidad Spnish Accounting Review, v. 18, n. 2, p. 148-161, 2015.

LI, Leon; KUO, Chii Shyan. CEO equity compensation and earnings management: The role of growth opportunities. Finance Research Letters, 2017.

MACEDO, Marcelo Alvaro da Silva; MACHADO, Márcio André Veras; MURCIA, Fernando Dal Ri; MACHADO, Márcia Reis. Análise do impacto da substituição da DOAR pela DFC: um estudo sob a perspectiva do value-relevance. Revista Contabilidade \& Finanças USP, São Paulo, v. 22, n. 57, p. 299-318, 2011.

MAJEWSKA, Agnieszka. The Formula of Exercise Price in Employee Stock Option - Testing of the Proposed Approach. Research Papers of Wroclaw University of Economic. 2015.

MARTINS, Eliseu; GELBCKE, Ernesto Rubens; SANTOS, Ariovaldo dos; IUDÍCIBUS, Sérgio de. Manual de Contabilidade Societária aplicável a todas as sociedades de acordo com as normas internacionais e do CPC. 2. ed. São Paulo: Atlas, 2013.

MEGAN, Ovidiu; HATEGAN, Camelia; CACIUC, Leonora; COTLET, Bogdan. The cash-flow statement - between true and manipulation. Annals of the University of Petrosani, Economics, 9(2), 127-136, 2009.

MURAVYEV, Alexander. Board of directors in Russian publicly traded companies in 1998-2014: Structure, dynamics and performance effects. Economic Systems, Russia, 2016.

NILAKANT, Venkataraman; RAO, Hayagreeva. Agency Theory and Uncertainty in Organizations: An Evaluation. Organization Studies, 1994. 
SELLERS, Keith; KING, Brett; HUANG, Yingping. Employee Stock Options: What Valuation Analysts Should Know. Business Valuation Update, v. 21, n. 4, 2015.

SESIL, James C; LIN, Yu Peng. The Impacto of Employee Stock Opition Adoption and Incidence of Productivity: Evidence from U.S Panel Data. Industrial Relations, v. 50, n. 3, 2011.

SILVA, Edilson dos Santos; SANTOS, Joséte Florêncio dos; ALMEIDA, Moisés Araújo. Conselho de Administração: uma análise da influência nos níveis de endividamento. Revista Brasileira de Gestão de Negócios FECAP, v. 13, n. 41. p. 440-453, 2011.

THEISS, Viviane; BEUREN, Ilse. O acionista controlador e a remuneração dos executivos nas empresas listadas na BM\&FBovespa. Revista Portuguesa e Brasileira de Gestão, Lisboa, v. 13, n. 1, 2014.

TINOCO, João Eduardo Prudêncio; ESCUDER, Sérgio Antônio Loureiro; YOSHITAKE, Mariano. O Conselho Fiscal e a Governança Corporativa: transparência e gestão de conflitos. Revista Contemporânea de Contabilidade. Florianópolis, v. 8, n. 16, 2011.

WOOD Jr., T; PICARELI FILHO, V. Remuneração e carreira por habilidades e competências. São Paulo: Atlas, 2004. 